\title{
Proceeding
}

Supplementary Issue: Spring Conferences of Sports Science. Costa Blanca Sports Science Events, 19-20 June 2020. Alicante, Spain.

\section{Tennis and learning through the Fit Junior Program: Observations and results for the didactics aim}

\author{
FEDERICA SANTOPIETRO $\triangleleft$, SIMONA FATTORE, FELICE DI DOMENICO, ITALO SANNICANDRO \\ University of Salerno, Italy
}

\begin{abstract}
For some years, the Italian Tennis Federation has made use of the national didactic evaluation and learning quality certification system of the Fit Junior Program, geared at accompanying young students on an introductory path consisting of a series of steps, with the aim of dividing learning into goals. With respect to this program, the aim of this study is to observe the learning of tennis within a group of "Dolphin level" beginner children, of the Potenza Tennis Club. Attention was focused on the evaluation of five technical aspects: strikes with feet planted firmly on the ground; strikes by swinging the racket forward; also uses the non-dominant limb; shifts body weight from back to front; and strikes the ball at the right time. Each of them has been assigned a value between 1 (poor skill) and 5 (excellent skill), based on the skills acquired by the child during the five months of observation. The children underwent an evaluation both before and after the training period. Through the use of the Pearson correlation, it can be said that the working method carried out has made it possible to achieve positive results, confirming the effectiveness and validity of the Fit Junior Program.
\end{abstract}

Keywords: Fit Junior Program; Youth tennis; Motor learning.

\section{Cite this article as:}

Santopietro, F., Fattore, S., Di Domenico, F., \& Sannicandro, I. (2020). Tennis and learning through the

Fit Junior Program: Observations and results for the didactics aim. Journal of Human Sport and

Exercise, 15(3proc), S619-S627. doi:https://doi.org/10.14198/ihse.2020.15.Proc3.14

Corresponding author. University of Salerno, Italy.

E-mail: f.santopietro1@studenti.unisa.it

Supplementary Issue: Spring Conferences of Sports Science. Costa Blanca Sports Science Events, 19-20 June 2020. Alicante, Spain.

JOURNAL OF HUMAN SPORT \& EXERCISE ISSN 1988-5202

(c) Faculty of Education. University of Alicante

doi:10.14198/jhse.2020.15.Proc3.14 


\section{INTRODUCTION}

Mini tennis: A sport in which you learn by playing and in which equipment, spaces and rules are tailor-made for children, allowing you to correctly and quickly learn technical skills (Raiola, 2020, Raiola, Altavilla, Raiola, 2017). At the heart of mini tennis's didactic proposal, there is a game that represents for us an absolute priority. As stated by the Italian Tennis Federation guidelines, learning follows several principles and takes into account multiple factors, related both to technique and psychology, not to mention motor and tactical ones. The first objective, in fact, is to create positive emotions in the child by helping him/her to develop a good image of himself/herself and his/her skills; for this reason, it is important that the mini tennis instructor take a gradual approach by acting according to increasing levels of difficulty, in order to ensure that the student keeps his/her motivation high and, above all, has fun. A child who approaches tennis must, therefore, be able to understand that the movements that appear complicated (because they require visual acuity, timing and a remarkable capacity for motor coordination) are, in fact, absolutely within his/her reach (Altavilla, Raiola, 2019, Altavilla et al, 2018, Altavilla, Raiola, 2015, D'Elia, Raiola, 2019, D'Elia et al, 2019, Invernizzi et al, 2020, 2014ab, 2008). The particularities of mini tennis concern the reduced size of the court, the net and the rackets, as well as the use of depressurized balls that have a lesser rebound than those generally used by adults. All this facilitates learning in children, because it makes tennis a fully accessible sport and, above all, allows greater effectiveness in the execution of the shots (Sgrò et al, 2018, 2017ab, 2016, 2009). Additionally, with rackets suitable for children of 5,6, and 7 years of age, and balls that bounce at heights appropriate to that of the students, one is able to set proper articulatory movements; thus the physical effort required is age-appropriate (Izzo et al, 2020ab, lzzo et al, 2019ab).

Furthermore, within the teaching of mini tennis, it is essential to work on the basic coordination skills that are developed and improved through games and activities that stimulate them: space, balance, reactivity and rhythm orientation (Sannicandro et al, 2017, 2016, 2015ab, 2014, 2012ab, 2011a, 2010). We have thus set upon ourselves the goal of focusing on observing the learning of tennis in a group of children who are approaching this space for the first time.

Attention was focused on the technical aspects; therefore, the goal was to home in on the learning of the technique, while working from a holistic perspective that includes not only technical but also mental, motor and tactical aspects.

\section{MATERIALS AND METHODS}

\section{Participants}

The observation lasted five months, from October 2019 to March 2020 and was carried out during biweekly training. The sample group consists of 12 children, including nine boys and three girls.

Table 1. Data collected.

\begin{tabular}{llllll}
\hline Name & DOB & Age 1st Survey & Age 2 2d $^{\text {survey }}$ & Weight & Height \\
\hline Student 1 & $29 / 09 / 2008$ & 11.1 yrs. & 11.6 yrs. & $36 \mathrm{Kg}$ & $142 \mathrm{~cm}$ \\
Student 2 & $11 / 12 / 2008$ & 10.10 yrs. & 11.3 yrs. & $35.5 \mathrm{Kg}$ & $140 \mathrm{~cm}$ \\
Student 3 & $30 / 05 / 2010$ & 9.5 yrs. & 9.10 yrs. & $29 \mathrm{Kg}$ & $130 \mathrm{~cm}$ \\
Student 4 & $20 / 07 / 2010$ & 9.3 yrs. & 9.8 yrs. & $25 \mathrm{Kg}$ & $120 \mathrm{~cm}$ \\
Student 5 & $09 / 12 / 2010$ & 8.10 yrs. & 9.3 yrs. & $23 \mathrm{Kg}$ & $122 \mathrm{~cm}$ \\
Student 6 & $31 / 01 / 2011$ & 8.9 yrs. & 9.2 yrs. & $34 \mathrm{Kg}$ & $136 \mathrm{~cm}$ \\
Student 7 & $21 / 06 / 2011$ & 8.4 yrs. & 8.9 yrs. & $22 \mathrm{Kg}$ & $120.5 \mathrm{~cm}$ \\
\hline
\end{tabular}




\begin{tabular}{llllll}
\hline Student 8 & $13 / 10 / 2011$ & 8 yrs. & $8.5 \mathrm{yrs}$. & $22.5 \mathrm{Kg}$ & $127 \mathrm{~cm}$ \\
Student 9 & $15 / 03 / 2012$ & $7.7 \mathrm{yrs}$. & $8 \mathrm{yrs}$. & $24.5 \mathrm{Kg}$ & $120 \mathrm{~cm}$ \\
Student 10 & $22 / 05 / 2012$ & $7.5 \mathrm{yrs}$. & $7.10 \mathrm{yrs}$. & $22.5 \mathrm{Kg}$ & $118 \mathrm{~cm}$ \\
Student 11 & $01 / 06 / 2012$ & $7.4 \mathrm{yrs}$. & $7.9 \mathrm{yrs}$. & $24 \mathrm{Kg}$ & $123 \mathrm{~cm}$ \\
Student 12 & $01 / 03 / 2014$ & $5.7 \mathrm{yrs}$. & $6 \mathrm{yrs}$. & $19.5 \mathrm{Kg}$ & $111 \mathrm{~cm}$ \\
\hline AVERAGE VALUES & $\mathbf{8 . 5}$ & $\mathbf{8 . 9}$ & $\mathbf{2 6 . 7}$ & 125.8 \\
\hline
\end{tabular}

\section{Procedures}

Five technical objectives have been obtained from the official instrument of the Italian Tennis Federation, the Fit Junior Program, and each of them has been assigned a value between 1 and 5 , based on the skills acquired by the child during the five months of observation.

1. Strikes with feet planted firmly on the ground: A primary objective in all technical skills is balance; in fact, it is appropriate to focus attention on the starting position, characterized by a broad support base and correct core posture. In going for the ball and during the execution of technical skills, students will have to assume a position of the body in order to procure good balance. From this point of view, hitting from the side with respect to the net (in "neutral stance") is particularly useful as it is easier to control the centre of gravity.

2. Strikes by swinging the racket forward: It is important to encourage students to perform various skills by imagining that they "cross the ball" thanks to a predominantly horizontal trajectory of the racket.

3. Also uses the non-dominant limb: The value of bilateral exercises, which must be considered an integral part of the ideal structure of a mini tennis lesson, is important.

4. Shifts body weight from back to front: Represents an aspect of priority importance in order to ensure quality in the execution of technical skills.

5. Strikes the ball at the right time: The key to an effective execution of technical skills is associated with rhythm. If students are able to recognize the direction, trajectory and speed of the incoming ball, then they will be easily reaching the ball and time preparatory movements.

How the objectives were achieved:

The exercises proposed to the sample group, with regard to the first technical objective, concerned some games designed mainly by the instructor:

- "Throwing" game: Each student, placed on one side of the court, must throw a ball beyond the net and immediately thereafter position himself/herself at the exact point where it bounced. The furthest throw wins.

- "Inside and outside" game: Represents the next step of the previous game, that is, where the goal is to throw the ball over the net but inside the boundary lines; otherwise the throw is invalid.

- "Bounce and catch" game: Each student has a cone in his/her hands; the instructor will throw a ball which must be caught by the child by making it enter inside the cone, after a single bounce.

- Balance game: Each student keeps a tennis ball between his/her knees while remaining on one foot (first the right foot and then the left foot). The goal is to maintain the position (without dropping the ball) for a time established by the instructor (a few seconds). 
- Jump competition: A short route with a start and endpoints is established, the students independently choose the foot on which to perform the task, hopping with the aim of reaching the finish line (previously identified by the instructor). The course is then repeated, changing the support foot.

With regard to the second and third objectives, the students were offered games and play activities; in particular:

- Game of "we hold the racket!": The rackets are placed on the ground and each student is asked to take his/her own from the middle portion ("open throat") with his/her non-preferred hand (the right for left-handers and the left for the right-handers). Students are asked to position the racket in front of the sideways body so that the dominant hand can be positioned on the ropes and slowly descend to the grip where it should be held.

- "High five" game: Students are shown the position that the body and the racket must take before striking the ball and they are asked to "give the ball a high five".

- Finally, the fourth and fifth objectives were trained through activities of:

- Balance (staying balanced on the back foot and then moving on the front foot only);

- Rhythm: Through the use of the metronome, which marks the time (established and regulated by the instructor), and "regulates" the action to be taken.

\section{Statistical analysis}

Two surveys of primary importance were made for the purpose of the study, the first at the beginning of the training path and the second at the end thereof.

In the data collection carried out in October 2019, it was possible to better observe the predisposition of each child regarding the objectives to be achieved and to notice a fairly homogeneous and general trend in which the students seemed to start from an almost similar skill level, from a motor point of view.

During the second survey, carried out in March 2020, it was possible to verify the progress/regress of each student for each set goal.

In both surveys, each goal was assessed by assigning a numerical value of 1 to 5 , where 1 indicated poor skill and 5 indicated excellent execution ability.

Ultimately, each of the five objectives was taken into consideration and the correlation was calculated by relating the values of the first survey with those of the second; the values obtained were indicative of what was expected from our study, i.e. an improvement.

\section{RESULTS}

From the first survey, it was possible to observe the predisposition of each student regarding the objectives to be achieved: 


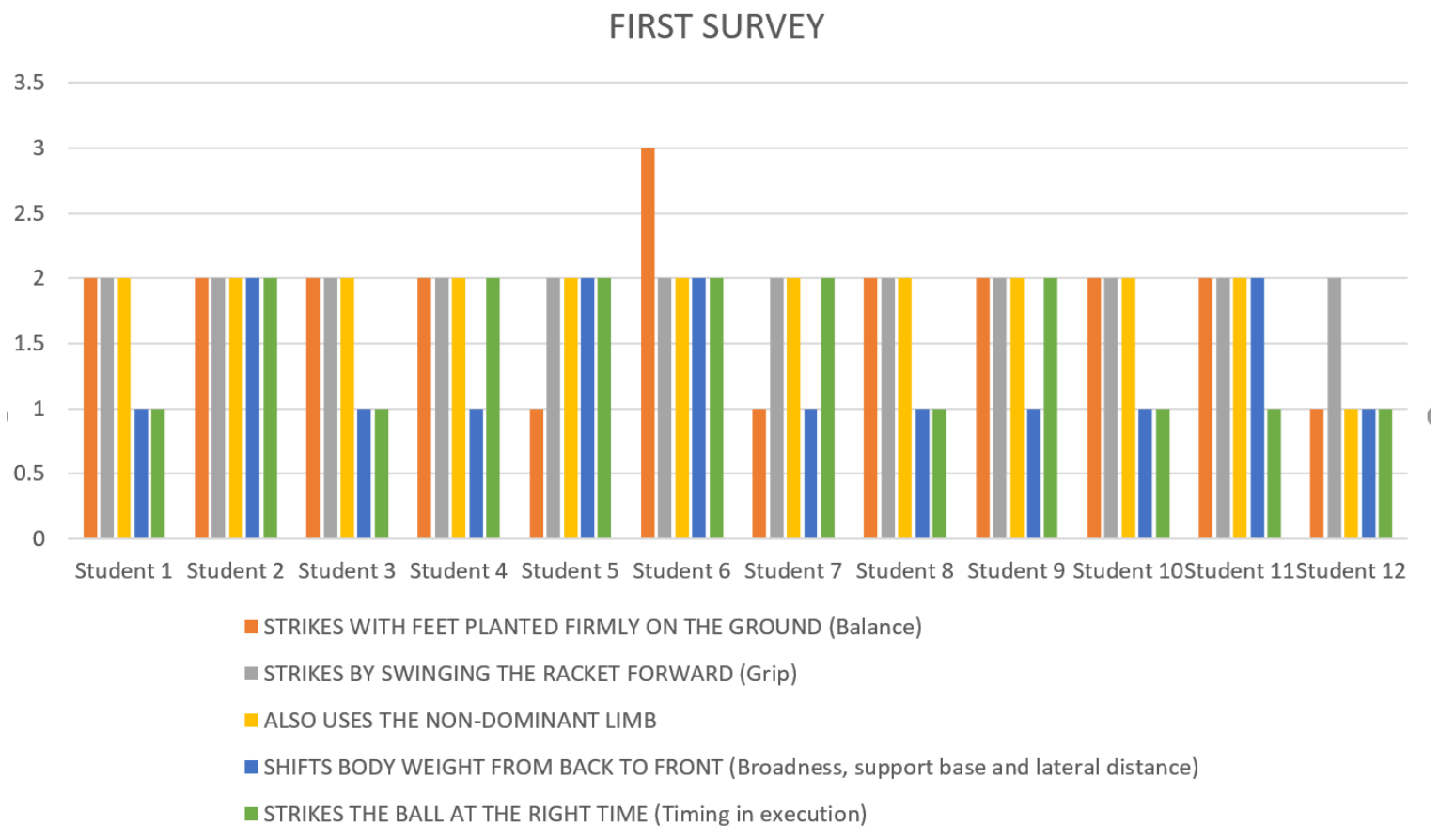

Figure 1. Incoming data.

During the training period, these values underwent a change based on the progress or otherwise of the students' skills, which were assessed by assigning a score of 1 to 5 :

Table 2. Score chart.

\begin{tabular}{llllll}
\hline Score & $\mathbf{1}$ & $\mathbf{2}$ & $\mathbf{3}$ & $\mathbf{4}$ & $\mathbf{5}$ \\
\hline $\begin{array}{l}\text { Competitive } \\
\text { standard }\end{array}$ & Very poor skill & Poor skill & $\begin{array}{l}\text { Sufficient } \\
\text { skill }\end{array}$ & Good skill & Very good skill \\
\hline Description & $\begin{array}{l}\text { Farregards the } \\
\text { required tasks or }\end{array}$ & $\begin{array}{l}\text { Correctly } \\
\text { the instructor's } \\
\text { requirements }\end{array}$ & $\begin{array}{l}\text { carries them out } \\
\text { correctly only with } \\
\text { support or } \\
\text { the required } \\
\text { guidance }\end{array}$ & $\begin{array}{l}\text { Hasks achieved } \\
\text { a level higher } \\
\text { than that } \\
\text { required }\end{array}$ & $\begin{array}{l}\text { Understands } \\
\text { and intuits the } \\
\text { overall playing } \\
\text { situation, } \\
\text { taking decisive } \\
\text { action }\end{array}$ \\
\hline
\end{tabular}

During the training period, these values underwent a change based on the progress or otherwise of the students' skills, which were assessed by assigning a score of 1 to 5 : 


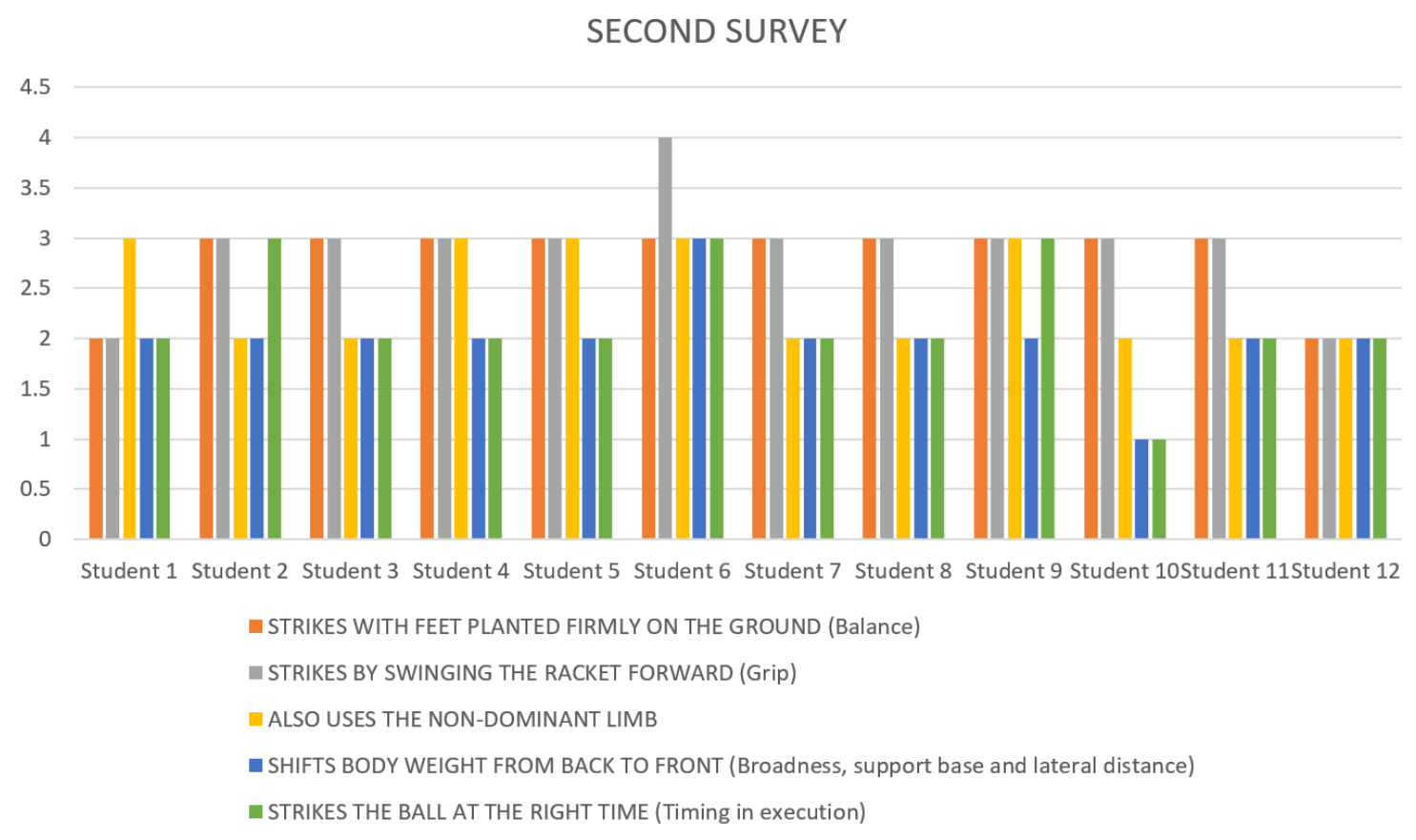

Figure 2. Outgoing data.

Finally, each of the five objectives was taken into consideration and the correlation was calculated by relating the values of the first survey with those of the second.

The values obtained are the following:

Table 3. Pearson correlation.

\begin{tabular}{ll}
\hline Objectives & Pearson index \\
\hline Strikes with feet planted firmly on the ground (balance) & 0.269679945 \\
Strikes by swinging the racket forward (grip) & - \\
Also uses the non-dominant limb & 0.254823596 \\
Shifts body weight from back to front (broadness, support base and lateral distance) & 0.433012702 \\
Strikes the ball at the right time (timing) & 0.603022689 \\
\hline
\end{tabular}

Table 4. Comparison correlation.

\begin{tabular}{lll}
\hline Type of Correlation & Reference Value & Our " $r$ " Value \\
Good, direct correlation & $0.5=r<1$ & $\begin{array}{l}r=0.60 \text { (Strikes the ball at the } \\
\text { right time) } \\
r=0.26 \text { (Strikes with feet planted } \\
\text { firmly on the ground) } \\
r=0.25 \text { (Uses the non-dominant } \\
\text { limb) } \\
r=0.43 \text { (Shifts body weight from } \\
\text { back to front) }\end{array}$ \\
\hline
\end{tabular}




\section{DISCUSSION}

The aim of the research was to observe the learning of tennis in a group of students who approached this sport for the first time. We observed how the activities proposed to the students were valid in order to show, at the end of the observation period, an improvement of our sample group.

From the incoming data, a fairly homogeneous and general trend can be seen; meaning the children seemed to start more or less from the same level, except an exceptional case in which, out of five skills, four were very scarce: the explanation could be due to the fact that the child in question, student 12, is the youngest of the group (5.7 yrs.).

During the training period, carried out in a playful way but trying to achieve specific goals, it was possible to note the progress of each child for each individual goal. In general, among the 12 children in the sample group, there are those who have improved in all abilities and those who only improved in some.

In fact, by looking at the outgoing data, it can be seen that student 12 filled the gaps present at the beginning of the course by reaching a uniform score for all skills and, also, the skills most learned (achieving a score of 3 , sufficient skill) were those related to striking the ball by swinging the racket forward and striking the ball while keeping both feet planted firmly on the ground, which entailed the use of the non-dominant limb.

By comparing the input data with the output data by applying the Pearson correlation, from the table that we obtained, we observe that all the values are > 0; therefore, this shows us the gradual improvement that occurred during the training period. Specifically, student 12 has achieved a uniform score for all skills (although he is still at a low level); the skills most learned were those related to striking the ball by swinging the racket forward and striking the ball while keeping both feet planted firmly on the ground, whereas the skill which was still difficult to acquire (but was, albeit slightly, improved to a score turns of 2, poor skill),was shifting body weight from back to front.

It is important to note the lack of the correlation index as regards the "strikes by swinging the racket forward" objective, and this is because, since the starting values were the same, the dispersion value was not detected.

Furthermore, given the similarity between the values collected and having used a rather narrow range (from 1 to 5), it was not considered appropriate to report the linear dispersion graph.

\section{CONCLUSIONS}

It can be said, therefore, that this observation work has allowed for the detection of improvement in the learning of tennis, and this can be seen from the fact that the correlation values are all $>0$.

The table shows how the work carried out has made it possible to achieve positive results by confirming the improvement towards the proposed objectives; each objective, therefore, can be achieved thanks to focused and constant work through the use of valuable guidance, as is the Fit Junior Program. 


\section{REFERENCES}

Altavilla, G., Raiola, G. (2019) A brief review on physiological commitment in basketball: An interpretative key, Journal of Human Sport and Exercise, 14, pp. S59-S65. https://doi.org/10.14198/ihse.2019.14.proc1.07

Altavilla, G., D'Elia, F., Raiola, G. (2018) A breif review of the effects of physical activity in subjects with cardiovascular disease: An interpretative key, Sport Mont, 16 (3), pp. 103-106. https://doi.org/10.26773/smj.181018

Altavilla, G., Raiola, G. (2015) Sports game tactic in basketball. Sport Science, 8 (1), pp. 43-46.

D'Elia, F., Raiola, G. (2019) Sport and Exercise Sciences Degrees in Italy: Comparison Between Online and Traditional Teaching Models, Communications in Computer and Information Science, 1091, pp. 209-216. https://doi.org/10.1007/978-3-030-31284-8_16

D'Elia, F., D'Isanto, T., \& Altavilla, G. (2019). Training and performance in the transition period. Journal of Human Sport and Exercise, 14(2proc), S258-S262. https://doi.org/10.14198//hse.2019.14.Proc2.15

Invernizzi, P.L., Signorini, G., Bosio, A., Raiola, G., Scurati, R. (2020) Validity and reliability of selfperception-based submaximal fitness tests in young adult females: An educational perspective Sustainability, 12 (6). https://doi.org/10.3390/su12062265

Invernizzi, P.L., Limonta, E., Bosio, A., Scurati, R., Veicsteinas, A., Esposito, F. (2014a) Effects of a 25$\mathrm{km}$ trial on psychological, physiological and stroke characteristics of short- And mid-distance swimmers Journal of Sports Medicine and Physical Fitness, 54 (1), pp. 53-62.

Invernizzi, P.L., Longo, S., Scurati, R., Maggioni, M.A., Michielon, G., Bosio, A. (2014b) Interpretation and perception of slow, moderate, and fast swimming paces in distance and sprint swimmers Perceptual and Motor Skills, 118 (3), pp. 833-849. https://doi.org/10.2466/27.29.pms.118k23w0

Invernizzi, P.L., Longo, S., Scurati, R. (2008) Analysis of heart rate and lactate concentrations during coordinative tasks: Pilot study in karate kata world champions Sport Sciences for Health, 3 (1-2), pp. 41-46. https://doi.org/10.1007/s11332-008-0053-7

Izzo, R., Raiola, G., D'isanto, T., Cejudo, A., Giovanelli, G.M. (2020a) Modelling an adequate profile for a more targeted work methodology, with dedicated technologies, for elite-level footballers: Comparison between sub 17 vs sub 19, highlights and shadows, Sport Science, 13 (1), pp. 36-42.

Izzo, R., D'isanto, T., Raiola, G., Cejudo, A., Ponsano, N., Varde'i, C.H. (2020b) The role of fatigue in football matches, performance model analysis and evaluation during quarters using live global positioning system technology at 50hz, Sport Science, 13 (1), pp. 30-35.

Izzo, R., Giovannelli, M., Raiola, G. (2019a) Training load in elite goalkeepers with k-track for monitoring performance, Journal of Physical Education and Sport, 19, art. no. 280, pp. 1890-1896.

Izzo, R., Giovannelli, M., D'isanto, T. (2019b) The injury prevention program WTA functional primitive movement in professional football players: A case study Journal of Physical Education and Sport, 19, art. no. 279, pp. 1885-1889.

Raiola, G., Altavilla, G. (2020). Testing motor skills, general and special coordinative, in young soccer. Journal of Human Sport and Exercise, 15(2proc), S206-S212. https://doi.org/10.14198/ihse.2020.15.proc2.11

Raiola, G. (2020) The Movement and Sport Science in Italy towards the European Research Council, Physical Culture and Sport, Studies and Research, 86 (1), pp. 37-48. https://doi.org/10.2478/pcssr2020-0011

Raiola, G. (2017) Motor learning and teaching method, Journal of Physical Education and Sport, 17, art. no. 236, pp. 2239-2243. 
Sannicandro, I. (2017) Effects of strength and core stability training versus strength and aerobic training in subjects aged over 65, Medicina dello Sport, 70 (4), pp. 410-418.

Sannicandro, I., Cofano, G., Rosa, A.R. (2016) Heart rate response comparison of young soccer plyers in "cage" small-sided and 8vs8 games Journal of Physical Education and Sport, 16 (4), art. no. 180, pp. 1122-1127.

Sannicandro, I., Spedicato, M., Palaia, G., Cofano, G., Bisciotti, G.N., Eirale, C. (2015a) Strength ability, endurance and anthropometric parameters in youth football: Descriptive analysis and functional relationships Medicina dello Sport, 68 (1), pp. 19-30.

Sannicandro, et al (2015b) Descriptive analysis and functional relationships, Medicina dello Sport, 68 (1), pp. 19-30.

Sannicandro, I., Piccinino, A., Cofano, G., Eirale, C., Biscotti, G.N. (2014) Effects of plyometric training on phases of jumping in young fencers, Medicina dello Sport, 67 (1), pp. 27-45.

Sannicandro, I., Piccinno, A., Cofano, G., De Pascalis, S., Rosa, A.R. (2012a) Analysis of some variable performances of under 12 tennis players, Medicina dello Sport, 65 (4), pp. 473-484.

Sannicandro, I., Rosa, R.A., De Pascalis, S., Piccinno, A. (2012b) The determination of functional asymmetries in the lower limbs of young soccer players using the countermovement jump. The lower limbs asymmetry of young soccer players Science and Sports, 27 (6), pp. 375-377. https://doi.org/10.1016/i.scispo.2011.11.001

Sannicandro, I. Evaluation of muscle strength in young and top-level soccer players (2011a), Medicina dello Sport, 64 (1), pp. 9-20.

Sannicandro, I., Piccinno, A., Cataleta, R., Maffione, E., De Pascalis, S. (2010) The fencing lunee: Analysis of load distribution to the lower limbs and gender-related differences in young fencers in relation to accident prevention, Medicina dello Sport, 63 (3), pp. 353-364.

Sgrò, F., Pignato, S., Lipoma, M. (2018) Assessing the impact of gender and sport practice on students 'performance required in team games Journal of Physical Education and Sport, 18, art. no. 71, pp. 497-502.

Sgrò, F., Quinto, A., Messana, L., Pignato, S., Lipoma, M. (2017a) Assessment of gross motor developmental level in italian primary school children Journal of Physical Education and Sport, 17 (3), art. no. 192, pp. 1954-1959.

Sgrò, F., Mango, P., Pignato, S., Schembri, R., Licari, D., Lipoma, M. (2017b) Assessing Standing Long Jump Developmental Levels Using an Inertial Measurement Unit Perceptual and Motor Skills, 124 (1), pp. 21-38. https://doi.org/10.1177/0031512516682649

Sgro', F., Quinto, A., Pignato, S., Lipoma, M. (2016) Comparison of product and process oriented model accuracy for assessing countermovement vertical jump motor proficiency in pre-adolescents Journal of Physical Education and Sport, 16 (3), art. no. 145, pp. 921-926.

Sgrò, F., Lo Bello, L., Lipoma, M. A networked embedded computing platform for physical activity assessment (2009) Proceedings - 2009 2nd Conference on Human System Interactions, HSI '09, art. no. 5090970, pp. 146-151. https://doi.org/10.1109/hsi.2009.5090970

\section{(9) $\odot \Theta \Theta$}

This work is licensed under a Attribution-NonCommercial-NoDerivatives 4.0 International (CC BY-NC-ND 4.0). 